\title{
Control of Shoot Tip Necrosis in Shoot Cultures of Portulaca grandiflora Hook.
}

\author{
Archana SRIVASTAVA, Aruna G.JOSHI* \\ The Maharaja Sayajirao University of Baroda, Faculty of Science, Department of Botany, \\ Vadodara-390002, India; drarunajoshi@yahoo.co.in ( ${ }^{*}$ corresponding author)
}

\begin{abstract}
Portulaca grandiflora, an important medicinal plant was found to show the incidence of shoot tip necrosis (STN) in shoot cultures obtained from nodal explants in Murashige and Skoog (MS) medium with 3\% sucrose along with $8 \mu \mathrm{M}$ Kinetin and $4 \mu \mathrm{M}$ BAP. This physiological disorder is primarily due to the deficiency of calcium and boron content in the medium. Thus in the present work varying concentration of boron which was used in the form of boric acid $(0.1-0.4 \mathrm{mM})$, calcium gluconate $(3-30 \mathrm{mM})$ and calcium chloride (3$30 \mathrm{mM}$ ) were incorporated in MS medium and its effect on STN was evaluated. The observations revealed that $18 \mathrm{mM}$ calcium chloride was the optimum concentration for lowering STN in shoot cultures to $40 \%$ after four weeks.
\end{abstract}

Keywords: Boron, calcium chloride, calcium gluconate, nodal explants

\section{Introduction}

Herbal medicines are most prevalently used by the people of developing countries for their primary health care needs and last decade has seen a considerable rise in pharmaceutical industries where plant extract is most abundantly employed. There is a fast depletion of these medicinally important plants from our environment because of their ruthless exploitation. Need has arisen where conservation and restoration of these plants should be done on priority basis for their sustainable usage. Micro propagation is a technique which could be utilized for the conservation of these medicinally important plants. Portulaca grandiflora (Portulacaceae) is a succulent ornamental herb associated with a number of medicinal properties. It is used for the cure of sore throat, skin rashes, putative immunostimulant (Chavalittumrong, 2007) contains betalain which is an antioxidant (Zryd, 1995), and the plant is antimutagenic (Liu, 1990). It has an efficacy on hepatitis B surface antigen (Zheng and Zhang, 1990), aerial parts are reported to contain various diterpenoids like portulal, portulenone, portulenol, portulene (Ohasaki et al., 1986) and portulene acetal a minor diterpenoid (Ohasaki et al., 1997). Regeneration of this plant was done with nodal explants (Srivastava and Joshi, 2009) and it was observed that the shoot cultures were affected with shoot tip necrosis after two weeks which lead to considerable loss of culture.

Shoot tip necrosis is a physiological disorder commonly observed in a number of in vitro cultured plants. The early visible symptoms of this anomaly are browning of the tip followed by basipetal necrosis. Senescence and death of the apical buds occurs which results in typical necrosis of the upper portion while the lower portion remains unaffected. Axillary buds produce shoots whose secondary branches also get affected. Lower branches and smaller shoots are also affected in severe cases. It can be because of a number of reasons such as nutrient deficiency ( $\mathrm{Ca}$ and B), concentration of cytokinins, medium type and its nutrient concentration, aeration, gelling agent, $\mathrm{pH}$ of the medium and subculture period (Bairu et al., 2009). Of all these deficiencies, $\mathrm{Ca}$ and $\mathrm{B}$ is one of the most common reasons for STN which results in less number of quality shoots, increased production cost and experimental errors (Barghchi and Alderson, 1996).

Thus a study was undertaken to find out the cause of STN in P. grandiflora and an experiment was devised by modifying the M.S medium with different concentration of $\mathrm{B}, \mathrm{Ca}$ gluconate and $\mathrm{CaCl}_{2}$.

\section{Materials and methods}

Nodal explants were obtained from a healthy population of mature plants of $P$. grandiflora growing in the Botanical Garden of the University. The explants were kept in running water for one hour, washed with a plant detergent for 5 minutes, and again rinsed four to five times thoroughly with sterile distilled water. Surface sterilization was done with $0.1 \%(\mathrm{w} / \mathrm{v}) \mathrm{HgCl}$ for 3 minutes and rinsed with autoclaved double distilled ${ }^{2}$ ater. The nodal explants were cut to appropriate size (2.5 to $3.0 \mathrm{~cm}$ in length) and inoculated vertically on the culture medium. Each treatment had 15 replicates and the experiment was repeated twice. 
46

The normal strength MS medium (Murashige and Skoog, 1962) was taken as control, where the concentration of $\mathrm{CaCl}_{2}$ is $3 \mathrm{mM}$ and $\mathrm{B}$ in the form of $\mathrm{H}_{3} \mathrm{BO}_{3}$ is $0.1 \mathrm{mM}$. The medium was supplemented with $3 \%$ sucrose, $8 \%$, agar, $8 \mu \mathrm{M}$ KIN and $4 \mu \mathrm{M}$ BAP, as it was optimized for nodal explants (Srivastava and Joshi, 2009) and was modified by adding different concentrations and source of $\mathrm{Ca}$ and $\mathrm{B}$, which is categorized as follows:

MS medium A- Source of B was boric acid in the concentration of $0.1,0.2,0.3$ and $0.4 \mathrm{mM}$

MS medium B-Source of Ca was calcium gluconate in the concentrations of $3,6,9,12,18,24$ and $30 \mathrm{mM}$

MS medium C-Cawas used in the form of $\mathrm{CaCl}_{2} \cdot 2 \mathrm{H}_{2} \mathrm{O}$ (which is the form used in standard M.S medium) in a concentration of $3,6,9,12.18,24$ and $30 \mathrm{mM}$.

The $\mathrm{pH}$ of the medium was adjusted to 5.8 and 20 $\mathrm{ml}$ of culture medium was dispensed in culture tubes. The medium as well as the instruments were autoclaved at $121^{\circ} \mathrm{C}$ for 30 minutes. All cultures were maintained at $25 \pm 2^{\circ} \mathrm{C}$ under a $12 \mathrm{~h}$ photoperiod of irradiance provided with white florescent tube.

\section{Statistical analysis}

The experiment was monitored for a period of 4 weeks and data for number of shoots per explant was recorded. Standard error of the mean for each value was calculated. Data was subjected to analysis of variance (ANOVA) and it was found to be statistically significant at $\alpha=0.1$ and $p$ value $<0.1$.

\section{Results}

During the regeneration studies of $P$. grandiflora through nodal explants it was observed that after one week there was browning of the shoot tips followed by necrosis in a basipetalous manner. The multiple shoots grew to a length of $2-3 \mathrm{~cm}$ and gradually a necrotic zone was observed in the upper region while the lower portion remained unaffected where the axillary buds gave rise to shoots (Fig. 2a). In severe cases these shoots as well as the secondary shoots arising from them were also affected. By second week the explants were affected with heavy shoot

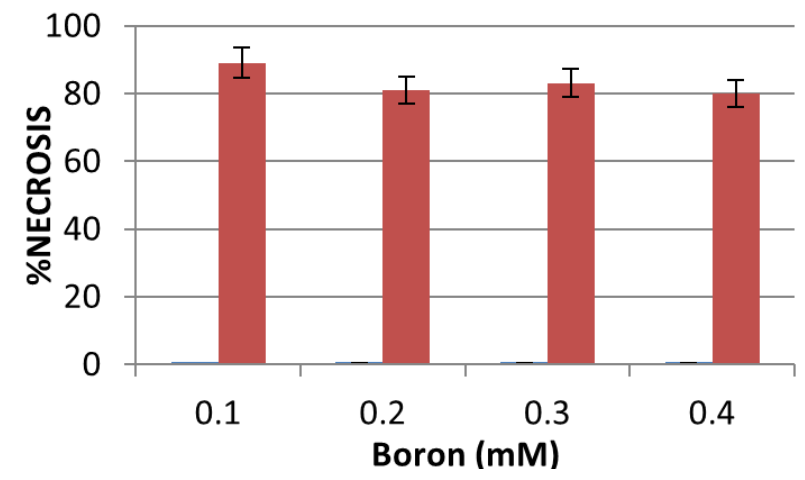

Fig. (1a). Percentage necrosis after four weeks for Medium A tip necrosis $(61.90 \%)$ which after four weeks was so severe that almost $90 \%$ of the shoot cultures were lost due to this anomaly (Fig. 1c). There was a clear cut necrotic zone in the upper region while the lower portion remained unaffected where the axillary buds gave rise to shoots (2a). In severe cases these shoots as well as the secondary shoots arising from them were also affected.

One of the effective methods of controlling STN in shoot cultures is by incorporating different concentrations of B and Ca salts in the medium (Bairu et al., 2009). Thus in the present study the effect of these two elements was evaluated and following results were obtained.

\section{MS medium A}

The MS medium was fortified with varying concentrations of $\mathrm{B}(0.1-0.4 \mathrm{mM})$ and the observations revealed that higher concentration of B in MS medium did not have any prominent effect on the rate of growth as well as STN (Fig. 1a).The number of shoots per explant decreased as the level of B increased from $0.1 \mathrm{mM}$ to $0.4 \mathrm{mM}$ (Tab. 1) and it failed to evoke any significant effect on STN.

\section{MS medium $B$}

When different concentrations of Ca gluconate (3-30 $\mathrm{mM}$ ) were added to the MS medium the nodal explants responded to this source of $\mathrm{Ca}$ as the number of shoots/ explant improved. The optimum number of shoots $(2.47 \pm 0.5)$ was formed at low concentration $(6 \mathrm{mM})$ and at high concentrations $(18-30 \mathrm{mM})$ a decline in response resulted. The incidence of STN was least at $9 \mathrm{mM}(40 \%)$ and again increased at higher concentrations (Tab. 1, Fig. 1b). Presence of this salt in the medium had an effect on the shoots as they had long internodes with pale green leaves.

\section{MS medium $C$}

$\mathrm{CaCl}_{2}$ is the normal source of $\mathrm{Ca}$ in MS medium, at a concentration of $3 \mathrm{mM}$ and at this level the rate of STN was very high (89\%)in shoot cultures. The medium was fortified with enhanced concentrations of $\mathrm{CaCl}_{2}(6-30$

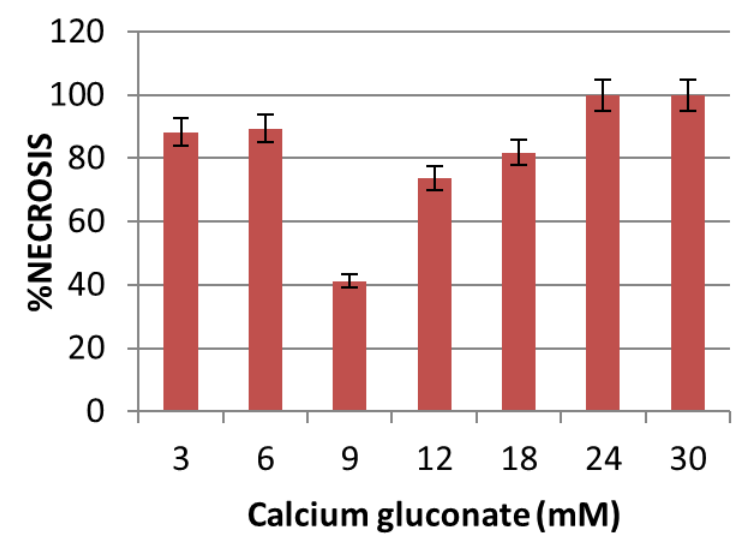

Fig. (1b). Percentage necrosis after four weeks for Medium B 


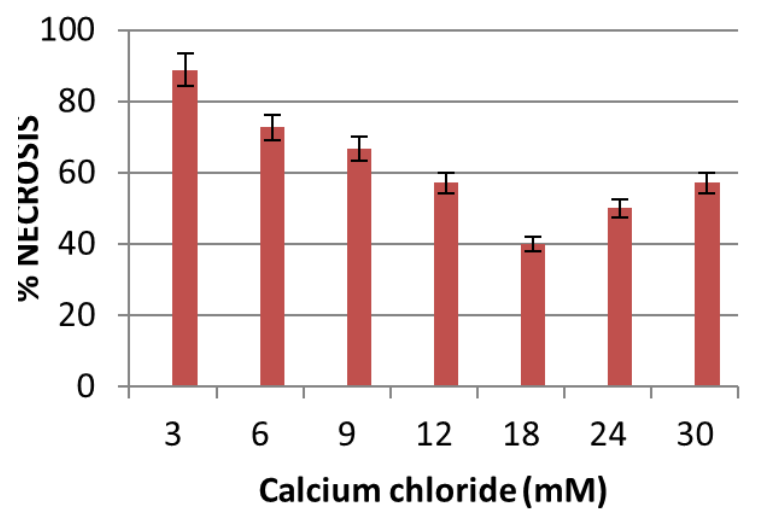

Fig. (1c). Percentage necrosis after four weeks for Medium C

$\mathrm{mM}$ ) and the observations revealed that the STN slowly decreased with higher levels (Fig. 2 b), with $18 \mathrm{mM}$ being optimum in reducing necrosis to $40 \%$ ( Fig. 1c). Further, rise in the level of $\mathrm{CaCl}_{2}$ failed to reduce \% necrosis. A similar pattern was observed for shoots/explant (Tab. 1) where $18 \mathrm{mM}$ concentration again proved to be suitable in inducing an optimum response $(2.83 \pm 0.30)$.

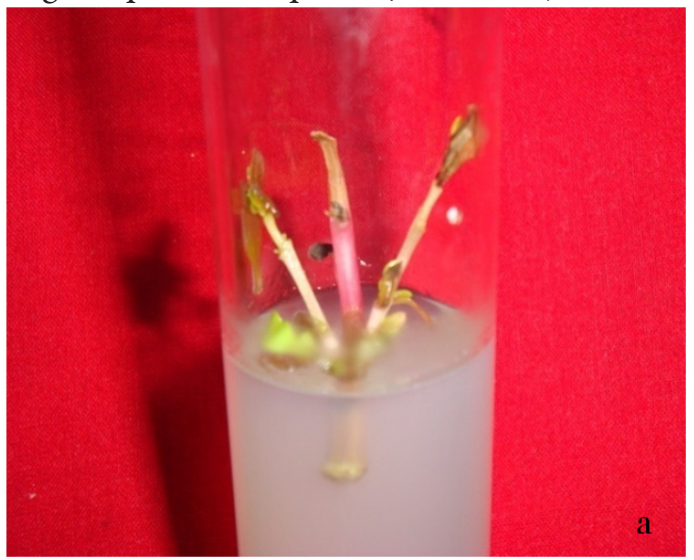

\section{Discussion}

Problem of shoot tip necrosis was of frequent occurrence when a study to understand the behaviour of nodal explant under the influence of cytokinins of $P$. grandiflora was undertaken (Srivastava and Joshi, 2009). Several hypotheses have been proposed for STN of which deficiencies of B (Mason and Gutteridge, 1974) and Ca (McCown and Sellmer, 1987; Sha et al., 1985) are reported to be the most likely cause of STN.

Boron is an essential element in plants. It is a constituent of cell wall and is involved in enzyme activation, membrane maintenance, nucleic acid metabolism and sugar translocation (Apostol and Zwiazek, 2004). Its requirement differ widely among plant species and are known to have a narrow range between deficiency and toxicity levels when compared to other mineral nutrients (Abdulnour et al., 2000). Deficiency of B leads to an inhibition in the rapid growth of root and shoot meristem ( $\mathrm{Hu}$ and Brown, 1994).

Medium A showed that there was no appreciable decrease in STN and dose of B beyond $0.4 \mathrm{mM}$ turned toxic. The number of shoots/explant also decreased with increasing concentration which could be due to its accumulation

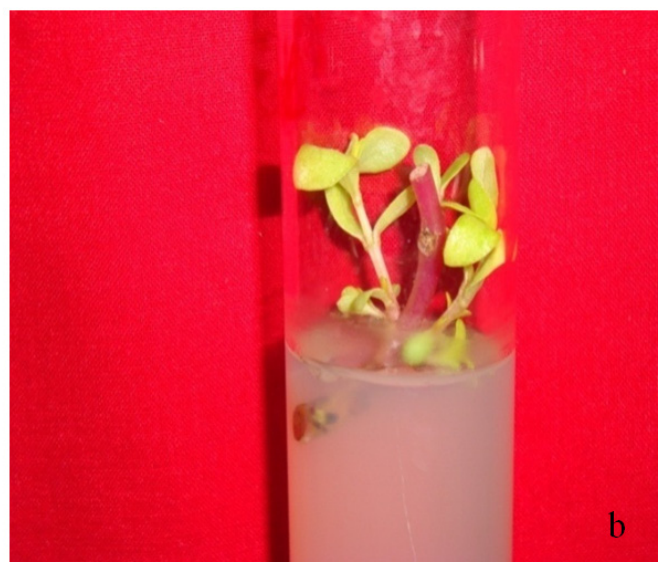

Fig. 2. STN incidence in P grandiflora - a) affected shoots on normal MS medium b) Healthy shoots at $18 \mathrm{mM}$ of Medium C

Tab. 1. Effect of Boron, Calcium gluconate and Calcium chloride on number of shoots / nodal explant (Mean \pm S.E) of $P$. grandiflora after four weeks of culture $(p<0.1)$

\begin{tabular}{|c|c|c|c|}
\hline \multicolumn{4}{|c|}{ Number of shoots (Mean \pm S.E.) } \\
\hline $\mathrm{mM}$ & Medium A (Boron) & Medium B (Ca gluconate) & Medium $\mathrm{CaCl}_{2}$ \\
\hline 0.1 & $1.83 \pm 0.24$ & & \\
\hline 0.2 & $1.68 \pm 0.21$ & & \\
\hline 0.3 & $1.50 \pm 0.56$ & & \\
\hline 0.4 & $1.40 \pm 0.87$ & & \\
\hline 3 & & $2.08 \pm 0.09$ & $1.83 \pm 0.24$ \\
\hline 6 & & $2.47 \pm 0.51$ & $1.63 \pm 0.38$ \\
\hline 9 & & $2.23 \pm 0.10$ & $2.5 \pm 0.32$ \\
\hline 12 & & $2.35 \pm 0.15$ & $2.12 \pm 0.39$ \\
\hline 18 & & $1.90 \pm 0.43$ & $2.83 \pm 0.30$ \\
\hline 24 & & $1.75 \pm 0.36$ & $2.50 \pm 0.18$ \\
\hline 30 & & $1.40 \pm 0.37$ & $2.07 \pm 0.12$ \\
\hline
\end{tabular}


48

in the shoot tissue (particularly in the lower parts) to a toxic level (Barghchi and Alderson, 1996). Similar results are reported in Pistacia vera (Abousalim and Mantell, 1994) where increasing concentration of B could not suppress STN and growth of the cultures were severely affected.

$\mathrm{Ca}$ is an essential divalent cation found in high concentration in plant tissues and it performs several physiological activities which are important for growth and development (Hepler and Wayne, 1985). It is also known to play a vital role in structural and functional signaling (Bairu, 2009). It strengthens the cell wall, provides stress tolerance, and stabilizes cell membranes by connecting various proteins and lipids at membrane surfaces. $\mathrm{Ca}$ is also involved in other physiological processes such as cell elongation, cell division and influencing the $\mathrm{pH}$ of the cells. In addition it has a role as a regulatory ion in the source sink translocation of carbohydrates (Hirschi, 2004; Marschner, 1995).

In a multiple cluster the central shoot showed symptoms for necrosis and lower axillary buds produced shoot. Similar observations were made on Vitis vinifera L. (Thomas, 2000) where axillary buds produced fresh sprouts whenever the shoot tip was affected and necrotic plants showed a lower level of $\mathrm{Ca}^{++}$and $\mathrm{Mg}^{++}$. The study suggested that deficiency of $\mathrm{Ca}$ could be a possible reason for STN. In crops like, potato, quince and Pistacia, STN has been attributed to the deficiency of $\mathrm{Ca}$, caused by high humidity and low transpiration in the closed culture vessels (Abousalim and Mantell, 1994; Sha et al., 1985; Singha et al., 1990;). Specifically in quince (Singha et al., 1990) it was observed that by increasing the level of $\mathrm{Ca}(30 \mathrm{mM})$, STN decreased but it was also associated with reduced growth. Considering these reports for the effect of $\mathrm{Ca}^{++}$in reducing STN two salts of calcium were employed in the present investigation. It was observed that in both MS medium $B$ and C, STN reduced by increasing the concentration of $\mathrm{Ca}$ ( 9 and $18 \mathrm{mM}$ respectively). Bairu et al. (2009) have also reported that, high concentration of $\mathrm{Ca}$ in the medium reduced STN without affecting growth and regeneration.

Medium B consisted of varying concentration of Ca gluconate as a Ca source instead of $\mathrm{CaCl}_{2}$ in the MS medium. Studies indicated that STN was least at $9 \mathrm{mM}$ concentration and $\mathrm{Ca}$ gluconate helped to overcome the problem of STN in Poplar and Hybrid Aspen (De Block, 1990).There are reports that it was also beneficial in reducing the STN symptoms in Pistacia vera (Abousalim and Mantell, 1994).

Medium $\mathrm{C}$ consisted of $\mathrm{Ca}$ in the form of $\mathrm{CaCl}_{2}$ and it was found to be the most effective source of $\mathrm{Ca}$ in various reports. In the present study also $\mathrm{CaCl}_{2}$ was found to reduce STN and did not interfere with the growth of the shoots. Similar results are reported in banana (Martin et al., 2007), Soymida febrifuga (Chiruvella et al., 2011) where $\mathrm{CaCl}_{2}$ could alleviate the problem. Barghchi and Alderson (1996) also reported $\mathrm{CaCl}_{2}$ as a better source of
Ca to control this malady as compared to calcium acetate in cultures of Pistacia vera. Increasing the level of $\mathrm{CaCl}_{2}$ in the MS medium was again found to reduce STN in Pyrus pyrifolia (Thakur and Kanwar, 2008) without hindering with the growth of the plant.

\section{Conclusions}

The present study revealed that increasing the concentration of $\mathrm{CaCl}_{2}$ to $18 \mathrm{mM}$ in the MS medium helped to reduce the problem of STN to an appreciable level without affecting the growth of the plants.

\section{References}

Abdulnour JE, Donnelley DJ, Barthakur NN (2000). The effect of boron on calcium uptake and growth in micro propagated potato plantlets. Potato Res 43:287-295.

Abousalim A, Mantell SH (1994). A practical method for alleviating shoot tip necrosis symptoms in vitro shoot cultures of Pistacia vera cv. 'Mateur'. J Hortic Sci 69(2):357-365.

Apostol KG, Zwiazek JJ (2004). Boron and water uptake in jack pine (Pinus banksiana) seedlings. Environ Experim Bot 51:145-153.

Bairu MW, Wendy A, Stirk J, Van Staden (2009). Factors contributing to in vitro shoot-tip necrosis and their physiological interactions. Plant Cell Tiss Org Cult 98:239-248.

Bairu MW, Jain N, Stirk WA, Dolezal K, Van Staden J (2009). Solving the problem of shoot-tip necrosis in Harpagophytum procumbens by changing the cytokinin types, calcium and boron concentrations in the medium. South African J Bot 75:122-127.

Barghchi M, Alderson PG (1996). The control of shoot tip necrosis in Pistacia vera L. in vitro. Plant Growth Regul 20:3135 .

Chavalittumrong P, Sriwanthana B, Rojanawiwat A, Kijphati R, Jitjuk B, Treesangsri W, Phadungpat, Bansiddhi J, Bunjob M (2007). Safety of the aqueous extract of Portulaca grandiflora Hook in healthy volunteers Songklanakarin. J Sci Technol 29(1):95-100.

Chiruvella KK, Mohammed A, Dampuri G, Ghante RG (2011). In vitro shoot regeneration and control of shoot tip necrosis in tissue culture of Soymida febrifuga (Roxb.) A. Juss. Plant Tiss Cult Biotech 21(1):11-25.

De Block M (1990). Factors influencing the tissue culture and the Agrobacterium tumefaciens-mediated transformation of hybrid Aspen and Poplar clones. Plant Physiol 93:11101116.

Hepler PK, Wayne RO (1985). Calcium and plant development. Annu Rev Plant Physiol 36:397-439.

Hirschi KD (2004). The calcium conundrum. Both versatile nutrient and specific signal. Plant Physiol 136:2438-2442.

$\mathrm{Hu} \mathrm{H}$, Brown PH (1994). Localization of boron in cell walls of squash and tobacco and its association with pectin: evidence 
for a structural role of boron in the cell wall. Plant Physiol 105:681-689.

Liu D, Yin X, Wang H, Zhou Y, Zhang Y (1990). Antimutagenicity screening of water extracts from 102 kinds of Chinese medicinal herbs. Zhongguo Zhong Yao Za Zhi 15:617-622.

Marschner H (1995). Mineral nutrition of higher plants, $2^{\text {nd }} \mathrm{Ed}$. Academic Press, Boston

Martin KP, Zhang C, Slater A, Madassery J (2007). Control of shoot necrosis and plant death during micro propagation of banana and plantains (Musa spp.). Plant Cell Tiss Org Cult 88:51-59.

Mason GF, Gutteridge CG (1974). The role of calcium, boron and some divalent ions in leaf tip burn of strawberry. Sci Hortic 2:299-308.

McCown BH, Sellmer JC (1987). General media and vessels suitable for woody plant culture, 4-16 p. In: Bonga JM, Durzan L (Eds.). Cell and tissue culture in forestry. General principles and biotechnology, vol 1. Martinus Nijhoff, Dordrecht.

Murashige T, Skoog R (1962). A revised medium for rapid growth and bioassays with tobacco tissue cultures. Physiol Plant 15:473-497.

Ohsaki A, Asaka Y, Kubota T, Shibata K, Tokoroyama T (1997). Portulene acetal, a novel minor constituent of Portulaca grandiflora with significance for the biosynthesis of Portulal. J Nat Prod 60:912-914.

Ohsaki A, Shibata K, Tokoroyama T, Kubota T, Naoki H (1986). Novel diterpenes with bicyclo[5.4.0] undecane skeleton from Portulaca grandiflora Hook, possible linking intermediates in the biosynthesis of Portulal. Chem Letters
1986:1585-1588.

49

Sha L, McCown BH, Peterson LA (1985). Occurrence and cause of shoot-tip necrosis in shoot cultures. J Am Soc Hortic Sci 110(5):631-6341.

Singha S, Townsend EC, Oberly GH (1990). Relationship between calcium and agar on vitrification and shoot-tip necrosis of quince (Cydonia oblonga Mill.) shoots in vitro. Plant Cell Tiss Org Cult 23:135-142.

Srivastava A, Joshi AG (2009). In vitro behavior of nodal explants of Portulaca grandiflora Hook under the influence of cytokines. Acta Univer Latviensis 753:43-48.

Thakur A, Kanwar JS (2008). Micropropagation of 'Wild pear' Pyrus pyrifolia (Burm F.) Nakai. II Induction of Rooting. Not Bot Hoti Agrobo 36 (2):104-111.

Thomas P (2000). Micro cutting leaf area, weight and position on the stock shoot influence root vigor, shoot growth and incidence of shoot tip necrosis in grape plantlets in vitro. Plant Cell Tiss Org Cult 61:189-198.

Zheng MS, Zhang ZY (1990). Anti-HBsAg herbs employing ELISA technique. Zhong Xi Yi Jie He Za ZHi 1990(10): 560-562.

Zryd JP, Hassani BD (1995). In vitro culture and plant regeneration of large flowered purslane. Plant Cell Tiss Org Cult 41:281-283. 